\title{
Advances in Remote Plasma Cleaning of Electron Microscopes and Charged Beam Instruments
}

Ronald Vane

XEI Scientific Inc., Redwood City, CA, USA.

When the very successful remote plasma cleaner, the Evactron ${ }^{\circledR}$ De-Contaminator ${ }^{\circledR}$, was developed in 1999 most SEMs in the field used diffusion pumps that pump using heated oil, and remote plasma cleaning of contamination in SEM chambers was only practical at roughing pump pressures above $\sim 200$ mTorr. These pressures allowed for cleaning above the crossover pressure of the high vacuum diffusion pumps, which in turn limited direct plasma cleaning to surfaces within $\sim 20$ to $\sim 40 \mathrm{~cm}$ from the plasma oxygen radical source. Cleaning of larger chambers required the contamination to either migrate to this near-plasma region, or for it to volatilize (outgas) and be transported by a carrier gas flow to the pump. At these pressures gas-phase recombination reactions and scattering both act to limit the cleaning range of the reactive oxygen species that flow downstream from the plasma. At pressures above 200 mTorr the direct cleaning range is limited to less than $25 \mathrm{~cm}$ and cleaning of more distant surfaces relied on slower indirect cleaning mechanisms.

Today most high-performance SEMs today are now supplied with turbo-molecular pumps (TMPs), and rough pumping of chambers is done through the TMP while the rotor accelerates. Indeed to decontaminate using the Evactron ${ }^{\circledR}$ often requires users to delay activating the TMP and use only the roughing pump to perform the plasma cleaning at pressures in the 200-600 mTorr range.

As the industry leader in remote plasma cleaning solutions, XEI Scientific is ever aware of the changing needs of the users of SEMs, TEMs, and other charged beam instruments as technology changes. For these users we identify four characteristics of remote plasma cleaning that are most important:

- No damage to both specimens and the instrument, minimal wear and tear

- Cleaning rates, range, and conditions compatible with process need

- Particulate and artifact suppression

- Ease of use

Below we report on our recent efforts to improve and expand the science of plasma decontamination processes, and how this improved understanding is now (or soon will be) made available to Evactron ${ }^{\circledR}$ users in our new products.

Hydrogen-based cleaning: Remote plasma cleaning that uses excited neutral gas species (radicals) to do chemical etching of surface contaminants from surfaces avoids sputter etch damage. Air as a plasma feedstock gas to make oxygen radicals avoids many safety concerns because air and the hydrocarbon reaction products $\mathrm{H}_{2} \mathrm{O}, \mathrm{CO}, \mathrm{CO}_{2}$, etc. are natural in the environment and made in very small quantities [1]. However the use of air or oxygen for oxygen radical cleaning can cause oxidation damage to metal surfaces (Ag and $\mathrm{Ru}$ at room temperature, many other metals at elevated temperatures).

Alternatively, Hydrogen plasmas produce reactive species that clean by a reduction process to remove hydrocarbons and form hydride products which can be removed by the vacuum pumps. While use of hydrogen does create safety concerns, the use of on-demand hydrogen generators minimize the volume of hydrogen present and proper handling of the vacuum pump exhaust remediates the small amounts of hazardous hydrides. Cleaning rates using hydrogen are comparable to those of $\mathrm{O}_{2}$ for hydrocarbon films we have studied. 
Cleaning Efficiency versus Power and Pressure: Cleaning rates and range are factors of pressure, power transferred to the plasma, and working gas. The pressure affects the mean free path and the number of molecules flowing into the plasma. For practical systems for EM cleaning pressures between 10 and 50 mTorr give the best trade-offs between range and cleaning rates. These pressures can be achieved on a turbo pumped instrument without slowing or stopping the turbo by flowing gas into the plasma at a low rate. Using these higher cleaning rates allows for a reduction in cleaning time, and by keeping the cleaning time short (1-10 minutes) pump heating is minimized. In some cases we have measured cleaning rates that are 1 to 2 orders of magnitude faster than measured at higher pressures.

Power transfer to the plasma is also a method to increase cleaning rates. Under identical conditions

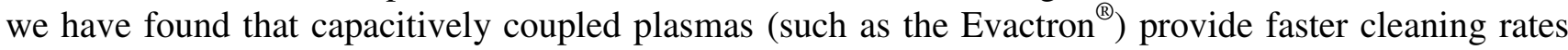
on a per-watt basis than alternative methods such as inductively coupled plasmas. We estimate that this is a result of our plasma excitation method being more effective at creating electrons with energy spectra that are better matched to the excitation cross-section of oxygen. For larger chambers higher power is useful to produce more radicals to treat a larger volume. Large Evactron ${ }^{\circledR}$ systems with 50 Watt RF supplies are now available for cleaning large chambers.

Control of Low Pressure Plasma Operation: The ease of use of the Evactron ${ }^{\circledR}$ cleaner has been improved by adding a new Evactron ${ }^{\circledR}$ cleaning mode for TMP-pumped chambers. With a high-speed turbo pump on the system, plasma gas feed rates of 15-25 sccm are tolerated and an Evactron plasma can be maintained at the lower pressures of 10 to $25 \mathrm{mTorr}$. At this pressure Evactron cleaning becomes faster and more uniform throughout the chamber and cleaning has been observed one meter from the source. While in the cleaning area a light pink plasma afterglow from a neutral nitrogen metastable transition is seen, our Langmuir probe studies show no significant ion population in the afterglow. Most important are the high cleaning rates achieved in this mode. The high cleaning rates indicate that the oxygen radical population is higher because recombination of oxygen is suppressed at these lower pressures by the significantly lower three body collision rates and decreased scattering to walls.

Ultra-Clean, Low Particle Plasma Cleaning: Each new generation of semiconductor processing and inspection equipment requires increasingly clean and particulate-free accessories on the various vacuum chambers used in IC fabrication. A new Evactron ${ }^{\circledR}$ system has been developed to meet these exacting standards and contains features including hydrogen-compatible materials, all-SS316L construction with metal seals on all joints and valves, a 50 watt generator, no exposure of the incoming gases to elastomers, in-line $3 \mathrm{~nm}$ particulate filter, a purgeable gas manifold to allow it to be added and removed from a vacuum chamber, and assembly and testing in a clean room. The gas control system uses a mass flow controller to achieve pressures in the 10-50 mTorr range suitable for a turbo pumped system.

Ease of Use: It has been the goal of the Evactron ${ }^{\circledR}$ control system to achieve simple one button operation for routine cleaning by users both in the direct control mode or through the back-panel computer interface. Interlocking to protect electron guns by monitoring the vacuum pressure is a standard option. With an Evactron ${ }^{\circledR}$ system that can operate with the turbopump at full speed further convenience and a shorter cleaning cycle is achieved.

[1]. For example, removing a monolayer of hydrocarbons from $1 \mathrm{~cm}^{2}$ results in a partial pressure of $\sim 10^{-6}$ Torr. 